\title{
Multiple Asymmetries and Exchange Rate Exposure at Firm Level: Evidence from Taiwan Stock Market
}

\author{
René Ferenc François (Franck) VARGA \\ Correspondence: René Ferenc François (Franck) VARGA, Department of Global Political Economy, Tamkang \\ University, Lanyang Campus, 180 Linwei Road, Jiaosi, Yilan County, ROC 26247, Taiwan. Tel: \\ 886-3-987-3088 ext.7133. E-mail: 134378@mail.tku.edu.tw
}

Received: June 23, 2012

doi:10.5539/ijef.v4n10p26
Accepted: August 6, 2012

Online Published: September 5, 2012

\begin{abstract}
It has been viewed as an unsolved puzzle that for only a small number of firms a significant impact of foreign exchange rate risk on firm value could be detected empirically even though the financial theory strongly supports that a change in the exchange rate should affect the value of the firm. We explain it by the facts that (i) previous studies mostly investigated mature and non-open economies and (ii) they mostly concentrated on one part of the relationship between exchange exposure and firm value. Our empirical results are based on a sample of 107 Taiwanese non-financial firms from $6^{\text {th }}$ June 1990 to $14^{\text {th }}$ July 2010 and the bilateral exchange rate USD / TWD. We use an orthogonalized model with conventional augmented CAPM specifications and asymmetric variables. Because the exposure cannot be viewed as a single coefficient, we also add GJR GARCH specifications to measure the asymmetric profile of the firms and the existence of asymmetric volatility of returns. Our findings show a strong exposure for most of our sample with exclusively a negative exposure (Taiwanese firms benefit from an appreciation of the domestic currency). We also find that exposure is non-linear. Moreover, the asymmetric profiles of the firms modify significantly their exposure. Finally, a high percentage of our monthly sample is affected by a positive coefficient of volatility of the stock returns associated with exchange rates changes but conversely for our daily sample. It means that the leverage of positive and negative shocks changes with the time horizon.
\end{abstract}

Keywords: economic exposure, exchange rate exposure, asymmetric exchange rate exposure, asymmetric volatility, open economy

\section{Introduction}

Since the breakdown of the Bretton Woods system in 1973, the volatility of exchange rates and its associated risks increase dramatically. Financial theory holds that exchange rate movements significantly affect firm value via their effects on the competitiveness of the firm's products, the cost of its inputs, the value of its foreign assets, its sensitivity to short-term cash flows (i.e. the probability of financial distress) and its cost of capital (i.e. growth opportunity).

But there is also much evidence from practitioners that exchange rate movements affect firms. Hung (1992) estimates for example that due to a strong dollar during the 1980s American manufacturers lost annually about USD23 billion, representing $10 \%$ of their gross profits. Rosenberg (2003) mentioned another survey which indicates that more than $45 \%$ of American companies are adversely affected by a strong dollar and later when the dollar weakened around 2002, various industries experienced higher exports and earnings.

This indicates that exchange rate movements affect both small and large firms. Without any doubt, similar observations have been made all around the world. The foreign exchange rate is even becoming a political tool. Academics and practitioners, all agree that fluctuations in foreign exchange rate are a source of uncertainty for the firm, regardless its size and whether the firm is domestically or internationally oriented. Empirical studies already document significant impacts of these fluctuations on firm cash flows, sales and competitive positions in product markets (Hung (1992), Williamson (2001)). Similarly, theoretical models predict that firms should display a significant exchange rate exposure (see for example Bodnar, Dumas and Marston (2002)).

A firm's exchange rate exposure refers to the sensitivity of its economic value (or stock price) to exchange rate changes (Heckman (1985)) or as stated by Adler and Dumas (1984), its economic exposure to exchange risk. If 
the volatility of exchange rates affect firm value (stock price), the question is to know how sensitive is the value of the firms to exchange rate movements. In another word, it means how the market prices the currency risk.

However, empirical studies have tended to document weak relations between exchange rate changes and firms' stock prices, if any at all. These studies include Jorion (1990, 1991), Amihud (1994), Bodnar and Gentry (1993), Bartov and Bodnar (1994), Griffin and Stuls (2001) or Dominguez and Tesar (2006), just to name some. In most of the studies, the percentage of firms displaying statistically significant exposures tends to be only about twice the chosen level of statistical significance, hence the term "exposure puzzle".

Bartram and Bodnar (2007) argue that the puzzle is mostly the result of "overly optimistic prior assumptions of the part of the researcher about the extent of significant exposures within a population of firms". They explain that low percentages of exposed firms are the result from "exposure reducing actions" which include both financial and operational hedging activities. Bartram, Brown and Minton (2010) show empirically that firms pass through part of currency changes to customers, which combined with operational hedging, each reduce firms' exposure by $10 \%$ to $15 \%$; moreover, financial hedging with foreign debt decreases exposure by about $40 \%$.

It seems that is why most of the studies finding significant exposures report a level of exposed firms lower than what one could expect: in average, between $10 \%$ and $25 \%$ of the sample, except for the few studies focusing particularly on open economies and nonlinear exposures. Moran (2005) for example found that $25 \%$ of his Chilean sample is exposed to the American dollar at the $10 \%$ level of significance. He also found that $54.7 \%$ of his sample, display a nonlinear exposure but none was asymmetrically exposed.

So, small and open economies seem to be a better laboratory to explore the exposure puzzle which is the main reason why we chose Taiwan. Taiwanese economy is clearly an open economy according Friberg and Nydahl (1999) criteria: if we compare the total trade to the GDP, the ratio is above $140 \%$ in 2008 compared for example to the $24 \%$ in USA. It is therefore worthwhile to investigate firms' exposure in a country with such high trade involvement. Moreover, Taiwan launched starting from July 1987 a financial liberalization program relaxing its control on capital account transactions. Exchange rate volatility started to increase at that time making the firms more sensitive to exchange rate movements. Our sample's period starts on June 1990, extending up to July 2010. The reminder of the paper is organized as follows. The next section presents related papers. Sample and methodology are described in section 3. Section 4 analyzes the main empirical results and section 5 concludes the paper.

\section{Asymmetric Exposure to Exchange Rate Risk: Related Papers}

An extensive literature followed the paper of Adler and Dumas (1984) which introduced a simple model with the stock return as the dependant variable and the change in the exchange rate as the explanatory variable. The resulting coefficient is the sensitivity of the firm to exchange rate movements. In a seminal paper, Jorion (1990) investigates it using a sample of 287 American multinational firms and an augmented market model (See Jorion (1990) and Bodnar and Wong (2000) for a discussion of why it is important to include the market return in equation (1)):

$$
R_{i, t}=\beta_{O, i}+\beta_{1, i} R m_{t}+\beta_{2, i} F X_{t}+\varepsilon_{i, t}
$$

With: $R_{i, t}$ denoting the stock return, $R m_{t}$ the return on the market index, and $F X_{t}$ the change in the exchange rate. But as mentioned in our introduction, very few authors find statistically significant exposure.

Thus, several changes in methodology are proposed since the seminal paper of Jorion (1990) such as the introduction of the lag effect or the time varying factors. We focus here on one particular change in methodology, the use of nonlinear and asymmetric exposure components.

Financial theory indicates that exposure should be at least for one part nonlinear, knowing that cash flows are a nonlinear function of the exchange rates. Several authors investigate asymmetric response to appreciations and depreciations, as Koutmos and Martin (2003), Bartram (2004), Carter et al. (2005) and Tai (2005).

But most of the results are mitigated even though Rossi (2009) finds that $38 \%$ of his Brazilian samples display a non linear exposure. According several authors such as Koutmos and Martin (2003) or Muller and Verschoor (2006), various reasons can generate a nonlinear relationship between the value of the firm and the exchange rate movements, mainly asymmetric hedging, incorrect pricing of assets, hysteresis for firms involved in international trade, magnitude of exchange rate fluctuations, pricing policies and market structures, and government interference. 


\subsection{Asymmetric Hedging}

One of the main factors to cause nonlinearity in the exchange rate exposure is the risk management chosen by the firm, through the use of hedging or financial derivatives. Firms always try to exploit opportunities and avoid adverse effects from macroeconomic changes, behavior which is reflected in their hedging strategies. It can generate nonlinear payoffs caused by the exchange rate movements leading to a nonlinear fluctuation of the cash flow and consequently the value of the firm. Options allow the company to make asymmetric gains (for example an importer will hedge against the depreciation of the domestic currency while making eventually a "profit" if the local currency appreciates) and the firm's exposure will also be influenced by the magnitude of the currency fluctuation, see Miller and Reuer (1998), Allayannis and Ofek (2001) or Rossi (2008). The use of real or financial options means that market-value exposures is larger to beneficial macroeconomic changes than to adverse ones since this kind of hedging allows to protect the firm against adverse changes and exploit beneficial fluctuations, see Andren (2001) for more details.

\subsection{Errors in Assets' Pricing}

Actors of the market may find uneasy to measure the consequences of an exchange rate movement on the firm's value especially in case of shocks. Indeed, it is difficult to identify if a shock is permanent of just temporary hence the problem to measure the real impact on the firm. Moreover, the way firms disclose their financial information (hedging policies...) is not always totally transparent thus creating the risk to mislead investors in their valuation process. Muller and Verschoor (2006) argue that may push investors into a "safe behavior" by ignoring lower magnitude of exchange rate movements and reacting more strongly to greater magnitude especially in case of "bad news", hence emphasizing the nonlinear component of the exposure.

\subsection{Hysteretic and Magnitude of Exchange Rate Change Asymmetries}

Another important source of asymmetry is the hysteretic behavior. If the depreciation of domestic currency persists, a number of new exporters may enter the market to benefit from the exchange rate movement. Therefore, the profits of the existing exporters may not increase as more firms are sharing the market. If the depreciation of the domestic currency is followed by a period of appreciation it is not sure that companies are in position to just quit the market, given the sunk costs the new comers had to pay. They are more likely to stay in the market with a lower profit or even losses in such a period. In these cases, the exchange rate fluctuations have a negative impact on the firm's value. This creates an asymmetry in exchange rate exposure. The decrease in profits during appreciations is larger than the increase in profits during depreciations. The phenomenon of hysteresis is logically supposed to occur after greater magnitude exchange rate movement, since small fluctuations will not influence companies in their entry or exit decisions. Therefore, magnitude of exchange rate changes is also a source of asymmetry in the firms' exposure. The magnitude leading to a response from the firm may depend on the company size, its industry, its past experience or macroeconomic factors. Thus the different responses of the firms to small and large exchange rate fluctuations give birth to the magnitude asymmetry of exchange rate exposure. The question remains in knowing for which threshold firms will start to respond and how long is supposed to be the period to attract new comers. See Baldwin (1988) and Dixit (1989) who describe hysteresis models.

\subsection{Pricing-to-market}

There are several studies describing pricing-to-market behavior of companies which is too, an important source of asymmetry of exchange rate exposure, see for example Froot and Klemperer (1989), Marston (1990) or Knetter (1994) who study this particular behavior which may take either two forms: pricing-to-market in view to maintain or improve the market share and pricing-to market under volume constraints. As Knetter (1994) states, the former form assumes that the firms' goal is to maximize their market share. So if the local currency appreciates, the exporter will not pass on the impacts to buyers by increasing the foreign prices of their products, to avoid the risk of losing market share to competitors from other countries. They may even be prone to reduce their export prices. On the contrary, if the domestic currency depreciates, exporters will maintain their mark-up at the same level, letting the export prices unchanged. Thus, they will not pass the benefits of depreciation by reducing the foreign prices of their goods. Consequently, exporters' profits may increase to a lesser degree during depreciation periods than decrease in appreciation periods. Pricing-to-market under volume constraints occurs because quota or wrong investment in marketing capacity (bottlenecks). On contrary to the previous behavior, the mechanism works in the other direction. In the case of a depreciation of the domestic currency exporters will not be able to increase their sales volume, because the volume constraints. Therefore, they may increase their foreign price to clear the market, being not interested in passing the benefit of depreciation to the 
buyers. In the opposite situation, if the domestic currency appreciates, exporters may let the foreign prices reflect the fluctuations and may not use the pricing-to-market: they will not reduce the foreign prices.

\subsection{Asymmetries due to Government Interference}

Government interference in the foreign exchange market may also be a source of asymmetry by indirectly helping domestic firms. If the exchange rate exceeds a certain level, the government may intervene to reduce the currency volatility and hence the firms' exposure. By limiting the appreciation of the domestic currency, it may help exporters and by controlling the depreciations of the local currency, it will help companies holding debts in foreign currencies.

\subsection{Asymmetry in Volatility of Stock Returns Underlying Exchange Rate Exposure}

The main explanation of the asymmetry in volatility of stock returns is the leverage effect, common concept in finance, through the leverage ratio debt / equity. Resulting from bad news, the negative return shock increases the leverage ratio and the volatility while good news will generate a positive return shock and a lower leverage ratio and volatility. But if we analyze the volatility of stock returns underlying exchange rate exposure, the picture is not so clear. When a domestic currency appreciates or depreciates, we cannot state that we are facing good or bad news. It will depend on the situation of the market participants (exporter, importer etc...) as mentioned by Bodnar and Gentry (1993). But a firm can play more than one role like for instance exporter and internationally priced input user. As Maghrebi et al. (2006) state, "whether depreciation of domestic currency should be viewed as good news or bad news is an open question". Other authors cite evidence for the existence of volatility asymmetry in stock returns related to exchange rate fluctuations as for instance Kanas (2000) and Giurda and Tzavalia (2004) so it seems that this volatility asymmetry is one of the exposure components we need to take into account, even though its mechanism is unclear.

\section{Methodology and Sample Description}

\subsection{Methodology}

There is a drawback of the above mentioned augmented CAPM models (Eq. 1). We cannot estimate the total impact of the exchange rate changes on stock returns as a single coefficient with this specification. Since market returns and exchange rate fluctuations are correlated, the influence of the latter on the firm value can be divided into two components: the direct exposure effect contained in $\beta_{2, i}$ and the indirect effect included in $\beta_{1, i}$. Alone, $\beta_{2, i}$ may under/overestimate the firm's true exposure to currency fluctuations. Moreover, these two effects may reinforce or offset each other. Under (Eq. 1) if exposure is zero, it does not mean that the firm has no exposure but just that its exposure is the same as the market. To address this issue, various authors use an auxiliary regression between market returns and exchange rate changes. The auxiliary regression is described as:

$$
R_{m, t}=\delta_{0}+\delta_{1} F X_{t}+\delta_{m, t}
$$

with $\delta_{m, t}$, the orthogonalized market returns, representing the component of market returns that is uncorrelated with exchange rate changes. We replace $R_{m, t}$ in (Eq. 1) by $\delta_{m, t}$. Substituting (Eq. 1-1) into (Eq. 1) and rearranging, we obtain the orthogonalized model:

$$
R_{i, t}=\beta_{0, i}^{*}+\beta_{1, i} \delta_{m, t}+\beta_{2, i}^{*} F X_{t}+\varepsilon_{i, t}
$$

where:

$$
\begin{aligned}
& \beta_{0, i}^{*}=\beta_{0, i}+\beta_{1, i} \delta_{0} \\
& \beta_{2, i}^{*}=\beta_{2, i}+\beta_{1, i} \delta_{1}
\end{aligned}
$$

$\beta_{o, i} \beta_{1, i}$ and $\beta_{2, i}$ are from the unorthogonalized model $R_{i, t}=\beta_{O, i}+\beta_{1, i} R m_{t}+\beta_{2, i} F X_{t}+\varepsilon_{i, t}$

The final purpose here is to capture both, sign asymmetry (responses from the firms after a depreciation or an appreciation of the domestic currency) and magnitude asymmetry (firms' reaction to small and large exchange rate fluctuations). We also use an orthogonalized version of the augmented CAPM specification but this time, by distinguishing asymmetric and exposure coefficients. In order to take into account specificities of financial time series as the time-varying volatility, we add a GARCH specification, more precisely a GJR GARCH $(1,1)$ which is able to accommodate asymmetry in volatility of stock returns which is as mentioned above, a stylized facts related to the exposure mechanism. We use dummy variables to measure the effects of an appreciation of the 
domestic currency (sign asymmetry) and a change in the exchange rate greater (magnitude asymmetry) than a specified filter (threshold), changing with the horizon.

The model is described as:

$$
R_{i, t}=\beta_{0, i}^{*}+\beta_{1, i} \delta_{m, t}+\left(\beta_{2, i}^{*}+\beta_{3, i} D_{\text {sign }, t}+\beta_{4, i} D_{\text {amp }, t}\right) F X_{t}+\varepsilon_{i, t}
$$

where:

$R_{i, t}$ is the return of the firm $\mathrm{i}$ at time $\mathrm{t}$

$\delta_{m, t}$ is the orthogonalized market return at time $\mathrm{t}$

$F X_{t}$ is the change in the USD/TWD exchange rate

$D_{\text {sign,t }}=1$ if $F X_{t}<0$ and 0 otherwise (dummy variable)

$D_{a m p, t}=1$ if $\left|F X_{t}\right|>\mathrm{x}$ and 0 otherwise (dummy variable).

The filter $\mathrm{x}=0.5 \%$ and $2 \%$ for respectively daily and monthly data.

The conditional variance equation $h_{i, t}$ is: $h_{i, t}=\omega_{i}+\alpha_{i} \varepsilon_{t-1}^{2}+\gamma_{i} D_{t-1} \varepsilon_{t-1}^{2}+\beta_{i} h_{i, t-1}$, where $D_{t-1}$ is equal to 1 if $\varepsilon_{i, t}$ is negative and 0 otherwise. The usual constraints related to GARCH models apply: $\omega_{i}>0$, $\alpha_{i}>0, \beta_{i}>0, \alpha_{i}+\gamma_{i}>0$ and $1 / 2\left(\alpha_{i}+\beta_{i}+\gamma_{i}\right)<1$.

In this model, it is associated to good news when $\varepsilon_{i, t}>0$ and bad news when $\varepsilon_{i, t}<0$. Both outcomes have differential effects on the conditional variance: good news has an impact on $\alpha_{i}$, while the bad news has an impact on $\left(\alpha_{i}+\gamma_{i}\right)$. If $\gamma_{i}>0$, bad news increases volatility (we say there is a "leverage effect"). If $\gamma_{i}$ is statistically significant, it implies the existence of an asymmetric volatility of stock returns underlying exchange rate exposure even though the mechanism through which it comes into being still remains unresolved. Depreciation or appreciation of the domestic currency is not automatically a good or bad news.

Table 1 summarizes the possible exposure coefficients according the various sign and magnitude changes in the exchange rate. $\beta_{2, i}^{*}$ and $\beta_{3, i}$ may be positive or negative according the position of the firm (exporter, importer, etc...) and we do not set constraints for the sign of $\beta_{4, i}$ which means that an exchange rate exposure associated with large fluctuations may be greater or lower than that of small changes. Indeed, Taiwanese firms may be more accustomed to relatively limited changes in the domestic currency (compared for instance to the JPY) given the Taiwan central bank policies. The various combination of the exposure and sign coefficients (respectively $\beta_{2, i}^{*}$ and $\beta_{3, i}$ ) mean different sources of asymmetry as mentioned in section 2 . In view to address this issue, we adopt the classification of Koutmos and Martin (2003).

Table 1. Impacts of various sign and magnitude fluctuations

\begin{tabular}{cc}
\hline Changes in exchange rate & Exposure coefficients \\
\hline Appreciation lower than the filter: & $\beta_{2, i}^{*}+\beta_{3, i}$ \\
$F X_{t}<0$ and $\left|F X_{t}\right|<\mathrm{x}$ & $\beta_{2, i}^{*}+\beta_{3, i}+\beta_{4, i}$ \\
\hline Appreciation greater than the filter: & $\beta_{2, i}^{*}$ \\
$F X_{t}<0$ and $\left|F X_{t}\right|>\mathrm{x}$ & $\beta_{2, i}^{*}+\beta_{4, i}$ \\
\hline Depreciation lower than the filter: & $F X_{t}>0$ and $\left|F X_{t}\right|<\mathrm{x}$ \\
\hline $\begin{array}{c}\text { Depreciation greater than the filter: } \\
F X_{t}>0 \text { and }\left|F X_{t}\right|>\mathrm{x}\end{array}$ \\
\hline
\end{tabular}

$\mathrm{x}=0.5 \%$ and $2 \%$ respectively for daily and monthly data 


\subsection{Sample Selection and Data Description}

All data are obtained from Taiwan Economic Journal Data Bank (TEJ). We only focus on non-financial Taiwanese companies listed on the Taiwan Stock Exchange (TSE).

Financial institutions are not included due to their different asset characteristics and objectives with regard to financial risks. This restriction makes also the sample comparable to the ones used in most of the previous studies.

Our purpose here, is to investigate the exchange rate exposure on the longest possible period of time, starting from 1990 (financial liberalization began mid of 1987 so we disregard the last years of the 1980s to avoid a structural break).

At the time of sampling, 741 companies are listed on the TSE (199 firms in 1990) but after eliminating companies with unavailable information and financial firms, the final sample consists of 107 firms with data starting on June 61990 and finishing on July 14 2010. This period of time covers almost 22 years. Tables A1 and A2 describe the selected firms. The sample selection may introduce a survivorship bias in the results. Since all these firms have survived during the sample period, they are likely to be the ones that have effectively managed various risk exposure. It means that the bias is against finding significant exposure coefficient.

Table A1. Sample: industries represented

\begin{tabular}{lcc}
\hline \multicolumn{1}{c}{ Industry Code } & Sample & Percentage \\
\hline 1 Cement & 5 & $4.67 \%$ \\
2 Foods & 8 & $7.48 \%$ \\
3 Plastics & 11 & $10.28 \%$ \\
4 Textile & 17 & $15.89 \%$ \\
5 Elec. \& Mach. & 4 & $3.74 \%$ \\
6 Elec. Appliance \& Cable & 8 & $7.48 \%$ \\
7 Chemicals & 11 & $10.28 \%$ \\
8 Glass \& Ceramics & 1 & $0.93 \%$ \\
9 Paper \& Pulp & 5 & $4.67 \%$ \\
10 Steel \& Iron & 6 & $5.61 \%$ \\
11 Rubber & 4 & $3.74 \%$ \\
12 Automobile & 1 & $0.93 \%$ \\
13 Electronics & 5 & $4.67 \%$ \\
14 Construction & 5 & $4.67 \%$ \\
15 Transportation & 3 & $2.80 \%$ \\
16 Tourism & 4 & $3.74 \%$ \\
17 Wholesale \& Retail & 7 & $6.54 \%$ \\
19 Others & 2 & $1.87 \%$ \\
\hline & 107 & $100.00 \%$ \\
\hline
\end{tabular}


Table A2. Sample list

\begin{tabular}{cccccccc}
\hline $\begin{array}{c}\text { Industry } \\
\text { Code }\end{array}$ & Fode & Code & Code & Code & Code & Code & Code \\
\hline 1 & 1101 & 4 & 1418 & 7 & 1713 & 14 & 2540 \\
1 & 1102 & 4 & 1419 & 7 & 1718 & 15 & 2601 \\
1 & 1103 & 4 & 1423 & 8 & 1802 & 15 & 2603 \\
1 & 1104 & 4 & 1434 & 9 & 1903 & 15 & 2605 \\
1 & 1108 & 4 & 1435 & 9 & 1904 & 16 & 2701 \\
2 & 1201 & 4 & 1441 & 9 & 1905 & 16 & 2702 \\
2 & 1210 & 4 & 1436 & 9 & 1907 & 16 & 2704 \\
2 & 1213 & 4 & 1437 & 9 & 1909 & 16 & 2705 \\
2 & 1215 & 4 & 1439 & 10 & 2002 & 17 & 2915 \\
2 & 1216 & 4 & 1440 & 10 & 2006 & 17 & 2913 \\
2 & 1217 & 4 & 1443 & 10 & 2007 & 17 & 2901 \\
2 & 1218 & 5 & 1503 & 10 & 2008 & 17 & 2903 \\
2 & 1229 & 5 & 1504 & 10 & 2009 & 17 & 2904 \\
3 & 1301 & 5 & 1506 & 10 & 2010 & 17 & 2905 \\
3 & 1303 & 5 & 1507 & 11 & 2102 & 17 & 2906 \\
3 & 1304 & 6 & 1605 & 11 & 2103 & 19 & 9904 \\
3 & 1305 & 6 & 1608 & 11 & 2104 & 19 & 9902 \\
3 & 1307 & 6 & 1609 & 11 & 2105 & & \\
3 & 1308 & 6 & 1611 & 12 & 2201 & & \\
3 & 1309 & 6 & 1603 & 13 & 2303 & & \\
3 & 1310 & 6 & 1604 & 13 & 2371 & & \\
3 & 1312 & 7 & 1701 & 13 & 2302 & & \\
3 & 1313 & 7 & 1702 & 13 & 2305 & & \\
3 & 1326 & 7 & 1704 & 13 & 2308 & & \\
4 & 1402 & 7 & 1707 & 13 & 2311 & & \\
4 & 1409 & 7 & 1708 & 13 & 2312 & & \\
4 & 1410 & 7 & 1709 & 14 & 2501 & & \\
4 & 1413 & 7 & 1710 & 14 & 2504 & & \\
4 & 1416 & 7 & 1711 & 14 & 2509 & & \\
4 & 1417 & 7 & 1712 & 14 & 2506 & & \\
\hline & & & & & & & \\
& & &
\end{tabular}

We decide to select the firm as the unit of analysis for several reasons.

Firstly, firms within the same industry are not homogenous and hence may display different exposure coefficients. Thus, individual exposure effects may be averaged out at the industry level.

Secondly, industry return indices are often value-weighted, advantaging large firms. As Dominguez and Tesar (2001) say, if small firms are more exposed to exchange rate fluctuations, analysis at the industry level will misjudge the true level of exposure.

Thirdly, asymmetry effects can best be captured at the firm level since an industry can include both exporters and importers.

Finally, if this study provides interesting conclusions, they may have a more practical impact and be more useful in exchange rate and assets management at the firm level.

As a proxy for the returns on the market portfolio, we use the TAIEX which is the main index in the Taiwan stock exchange.

We choose to employ a bilateral exchange rate instead of an exchange rate index to avoid its aggregated effects issues. Moreover, an exchange rate index is not always relevant for a firm. Currency changes may be measured in nominal and real terms.

We choose to use the nominal exchange rate firstly because it avoids the trouble to adjust the other variables of our regressions for consistency purposes (Khoo (1994)) and secondly, Mark (1990) finds that nominal and real 
changes are almost perfectly correlated for the seven countries used in his study. His conclusion is also shared by Atindehou and Gueyie (2001).

The American dollar is the currency mostly used by Taiwanese firms so as the nominal bilateral exchange rate we employ the USD / TWD (amount of Taiwanese dollar for one unit of American dollar). If the exchange rate change is negative (positive), the domestic currency (TWD) is appreciating (depreciating). If the firm displays a negative exposure coefficient, it will benefit from an appreciation of the TWD and if the exposure coefficient is positive, the firm will benefit from a depreciation of the domestic currency. We have respectively for daily and monthly data, 5245 and 240 individual observations representing 571,705 daily observations and 26,160 monthly observations over the sample period.

\section{Empirical Results and Major Findings}

\subsection{Multiple Asymmetries and Exchange Rate Exposure}

Table 2 provides the main results. The model measures individually each asymmetry and the exposure to see how the latter may be influenced by the former.

Table 2. Horizon Comparison: Model GJR GARCH multiple asymmetries

$$
R_{i, t}=\beta_{0, i}^{*}+\beta_{1, i} \delta_{m, t}+\left(\beta_{2, i}^{*}+\beta_{3, i} D_{\text {sign }, t}+\beta_{4, i} D_{a m p, t}\right) F X_{t}+\varepsilon_{i, t}
$$

With: $R_{m, t}=\delta_{0}+\delta_{1} F X_{t}+\delta_{m, t}, \quad D_{\text {sign,t }}=1$ if $F X_{t}<0$ and 0 otherwise and $D_{a m p, t}=1$ if $\left|F X_{t}\right|>\mathrm{x}$ and 0 otherwise. $\mathrm{x}=0.5 \%$ and $2 \%$ for respectively daily and monthly data. The conditional variance equation $h_{i, t}$ is: $h_{i, t}=\omega_{i}+\alpha_{i} \varepsilon_{t-1}^{2}+\gamma_{i} D_{t-1} \varepsilon_{t-1}^{2}+\beta_{i} h_{i, t-1}$, where $D_{t-1}$ is equal to 1 if $\varepsilon_{i, t}$ is negative and 0 otherwise. The usual constraints related to GARCH models apply: $\omega_{i}>0, \alpha_{i}>0, \beta_{i}>0, \alpha_{i}+\gamma_{i}>0$ and $1 / 2\left(\alpha_{i}+\beta_{i}+\gamma_{i}\right)$ $<1$

\begin{tabular}{|c|c|c|c|c|c|c|c|c|c|}
\hline \multicolumn{4}{|l|}{ Daily Model } & \multicolumn{2}{|c|}{$\begin{array}{c}\text { Sample Size } \\
\text { Average Adj R }{ }^{2}\end{array}$} & \multicolumn{2}{|l|}{$\begin{array}{c}105 \\
34.78 \%\end{array}$} & & \\
\hline \multicolumn{2}{|l|}{ Firms Exposed at } & \multicolumn{2}{|r|}{$\beta 2$} & \multicolumn{2}{|c|}{$\beta 3$} & \multicolumn{2}{|c|}{$\beta 4$} & \multicolumn{2}{|c|}{$\gamma$} \\
\hline & $10 \%$ & 93 & $88.57 \%$ & 15 & $14.29 \%$ & 13 & $12.38 \%$ & 40 & $38.10 \%$ \\
\hline & $5 \%$ & 90 & $85.71 \%$ & 11 & $10.48 \%$ & 11 & $10.48 \%$ & 35 & $33.33 \%$ \\
\hline & $1 \%$ & 77 & $73.33 \%$ & 3 & $2.86 \%$ & 5 & $4.76 \%$ & 19 & $18.10 \%$ \\
\hline & & \multicolumn{2}{|r|}{$\beta 2$} & \multicolumn{2}{|c|}{$\beta 3$} & \multicolumn{2}{|c|}{$\beta 4$} & \multicolumn{2}{|c|}{$\gamma$} \\
\hline & & $>0$ & $<0$ & $>0$ & $<0$ & $>0$ & $<0$ & $>0$ & $<0$ \\
\hline$\%$ of Exposed & & $0.00 \%$ & $100.00 \%$ & $6.67 \%$ & $93.33 \%$ & $69.23 \%$ & $30.77 \%$ & $37.50 \%$ & $62.50 \%$ \\
\hline Mean & & & -0.649 & 0.380 & -0.347 & 0.426 & -0.500 & 0.026 & -0.029 \\
\hline Median & & & -0.617 & & -0.324 & 0.435 & -0.504 & 0.026 & -0.028 \\
\hline Standard Deviation & & & 0.202 & & 0.059 & 0.100 & 0.089 & 0.007 & 0.012 \\
\hline Maximum & & & -0.299 & & -0.284 & 0.584 & -0.407 & 0.043 & -0.015 \\
\hline Minimum & & & -60.373 & & -0.511 & 0.275 & -0.584 & 0.017 & -0.059 \\
\hline \multicolumn{4}{|l|}{ Monthly Model } & \multicolumn{2}{|c|}{ Sample Size } & \multicolumn{2}{|l|}{102} & & \\
\hline \multirow{2}{*}{\multicolumn{2}{|c|}{ Firms Exposed at }} & \multirow{2}{*}{\multicolumn{2}{|c|}{$\beta 2$}} & \multirow{2}{*}{\multicolumn{2}{|c|}{$\begin{array}{c}\text { Average Adj } R^{2} \\
\mathbf{\beta 3}\end{array}$}} & \multirow{2}{*}{\multicolumn{2}{|c|}{$37.84 \%$}} & & \\
\hline & & & & & & & & \multicolumn{2}{|c|}{$\gamma$} \\
\hline & $10 \%$ & 65 & $63.73 \%$ & 11 & $10.78 \%$ & 6 & $5.88 \%$ & 58 & $56.86 \%$ \\
\hline & $5 \%$ & 55 & $53.92 \%$ & 7 & $6.86 \%$ & 3 & $2.94 \%$ & 51 & $50.00 \%$ \\
\hline \multirow{3}{*}{\multicolumn{2}{|c|}{$1 \%$}} & 27 & $26.47 \%$ & 4 & $3.92 \%$ & 1 & $0.98 \%$ & 33 & $32.35 \%$ \\
\hline & & \multicolumn{2}{|r|}{$\beta 2$} & \multicolumn{2}{|c|}{$\beta 3$} & \multicolumn{2}{|c|}{$\beta 4$} & \multicolumn{2}{|c|}{$\gamma$} \\
\hline & & $>0$ & $<0$ & $>0$ & $<0$ & $>0$ & $<0$ & $>0$ & $<0$ \\
\hline$\%$ of Exposed & & $0.00 \%$ & $100.00 \%$ & $27.27 \%$ & $72.73 \%$ & $50.00 \%$ & $50.00 \%$ & $60.34 \%$ & $39.66 \%$ \\
\hline Mean & & & -2.581 & 2.195 & -2.978 & 2.191 & -1.912 & 0.238 & -0.417 \\
\hline Median & & & -2.580 & 2.204 & -2.315 & 1.875 & -1.815 & 0.191 & -0.279 \\
\hline Standard Deviation & & & 0.653 & 0.572 & 2.088 & 1.006 & 0.549 & 0.170 & 0.318 \\
\hline Maximum & & & -1.303 & 2.762 & -1.606 & 3.316 & -1.418 & 0.791 & -0.054 \\
\hline Minimum & & & -4.242 & 1.618 & -8.055 & 1.381 & -2.503 & 0.033 & -1.237 \\
\hline
\end{tabular}

We find strong evidence of the presence of exchange rate exposure. At the $10 \%$ level of significance, $88.57 \%$ of the sample is exposed to daily foreign exchange changes; $14.29 \%$ exhibit a daily sign asymmetry and $12.38 \%$ a daily magnitude asymmetry. Monthly percentages are respectively $63.73 \%, 10.78 \%$ and $5.88 \%$. 
The percentage of exposed firms to foreign exchange risk decreases sharply when the horizon increases. The same comment can be made as well for the firms displaying sign and magnitude asymmetries.

All exposure coefficients are negative, with an average level of -0.649 and -2.581 for daily and monthly respectively. Table 3 exhibits the different forms of exposure and asymmetries obtained from the model.

Table 3. Forms of Exposure and Asymmetries (Level of significance used: 10\%)

\begin{tabular}{lccccc}
\hline \multicolumn{1}{c}{ Firms Displaying: } & Coefficients & \multicolumn{2}{c}{ Daily Data } & Monthly Data \\
\hline Exchange Rate Exposure & $\beta 2$ & 93 & $88.57 \%$ & 65 & $63.73 \%$ \\
Sign Asymmetry & $\beta 3$ & 15 & $14.29 \%$ & 11 & $10.78 \%$ \\
Magnitude Asymmetry & $\beta 4$ & 13 & $12.38 \%$ & 6 & $5.88 \%$ \\
Asymmetric Volatility & $\gamma$ & 40 & $38.10 \%$ & 58 & $56.86 \%$ \\
Exposure and Sign Asymmetry & $\beta 2$ and $\beta 3$ & 14 & $13.33 \%$ & 5 & $4.90 \%$ \\
Exposure and Magnitude Asymmetry & $\beta 2$ and $\beta 4$ & 10 & $9.52 \%$ & 3 & $2.94 \%$ \\
Exposure and Asymmetric Volatility & $\beta 2$ and $\gamma$ & 37 & $35.24 \%$ & 38 & $37.25 \%$ \\
Sign and Magnitude Asymmetries & $\beta 3$ and $\beta 4$ & 3 & $2.86 \%$ & 3 & $2.94 \%$ \\
Sign and Volatility Asymmetries & $\beta 3$ and $\gamma$ & 5 & $4.76 \%$ & 5 & $4.90 \%$ \\
Magnitude and Volatility Asymmetries & $\beta 4$ and $\gamma$ & 5 & $4.76 \%$ & 4 & $3.92 \%$ \\
All Three Asymmetries & $\beta 3$ and $\beta 4$ and $\gamma$ & 3 & $2.86 \%$ & 1 & $0.98 \%$ \\
Only Asymmetric Volatility & Only $\gamma$ & 30 & $28.57 \%$ & 16 & $15.69 \%$ \\
No Asymmetry at All & No $\beta 3$ and $\beta 4$ and $\gamma$ & 42 & $40.00 \%$ & 24 & $23.53 \%$ \\
At Least One Form of Asymmetry & $\beta 3$ or $\beta 4$ or $\gamma$ & 63 & $60.00 \%$ & 78 & $76.47 \%$ \\
\hline
\end{tabular}

Sign and magnitude asymmetries are more present when using daily data. $13.33 \%$ of the sample display simultaneous exposure and sign asymmetry and $9.52 \%$ an exposure and magnitude asymmetry; $2.86 \%$ of the firms display both asymmetries.

The percentage of firms displaying sign and magnitude asymmetries decreases with the horizon, but the situation is reversed for the volatility asymmetry: it increases from $38.10 \%$ to $56.86 \%$ (respectively for daily and monthly data at the $10 \%$ significance level).

The percentage of exposed firms displaying a volatility asymmetry is respectively $35.24 \%$ and $37.25 \%$ for daily and monthly data, which also shows an increase with the horizon.

We checked if the fact to belong to a particular industry may explain the value of the Betas (exposure, sign and magnitude). For both, daily and monthly data, no specific pattern emerged.

So the industry is not an explanatory variable, at least for Taiwan. This fact is already a significant result.

\subsubsection{Sign Asymmetry in Exchange Rate Exposure}

In order to describe the sources of sign asymmetry, we use the classification in Koutmos and Martin (2003), with daily and monthly data. The results are summarized in Tables 4 and 5 . 
Table 4. Possible Sources of Sign Asymmetry of Exchange Rate Exposure: Daily Data

\begin{tabular}{|c|c|c|c|}
\hline & $\beta 2>0$ & $\beta 2=0$ & $\beta 2<0$ \\
\hline$\beta 3>0$ & $\begin{array}{l}\text { \#Net Exporters } \\
\text { \#Pricing-to-Market } \\
\text { With Market } \\
\text { Share Objective } \\
\text { \#Hysteresis } \\
\text { 0 firm (0.00\%) }\end{array}$ & $\begin{array}{l}\text { \#Net Exporters } \\
\text { \#Pricing-to-Market } \\
\text { With Market } \\
\text { Share Objective } \\
\text { \#Hysteresis } \\
\text { 0 firm (0.00\%) }\end{array}$ & $\begin{array}{l}\text { \#Net Importers } \\
\\
\text { \#Pricing-to-Market } \\
\text { With Market } \\
\text { Share Objective }\end{array}$ \\
\hline $\boldsymbol{\beta 3}=\mathbf{0}$ & $\begin{array}{l}\text { \#Net Exporters } \\
\text { \#Symmetric } \\
\text { Exposure } \\
\text { 0 firm (0.00\%) }\end{array}$ & $\begin{array}{l}\text { \#Net Exporters or } \\
\text { Importers } \\
\text { \#No Exposure } \\
\mathbf{1 1} \text { firms (10.48\%) }\end{array}$ & $\begin{array}{l}\text { \#Net Importers } \\
\text { \#Symmetric } \\
\text { Exposure } \\
\text { 79 firms (75.24\%) }\end{array}$ \\
\hline$\beta 3<0$ & $\begin{array}{l}\text { \#Net Exporters } \\
\text { \#Pricing-to-Market } \\
\text { Under Volume } \\
\text { Constraints } \\
\\
\text { \#Asymmetric } \\
\text { Hedging } \\
\text { 0 firm (0.00\%) }\end{array}$ & \begin{tabular}{|l} 
\#Net Importers \\
\#Pricing-to-Market \\
Under Volume \\
Constraints \\
\\
\#Asymmetric \\
Hedging \\
\\
$\mathbf{1}$ firm (0.95\%)
\end{tabular} & $\begin{array}{l}\text { \#Net Importers } \\
\text { \#Asymmetric } \\
\text { Hedging }\end{array}$ \\
\hline
\end{tabular}

Adopted from Koutmos and Martin (2003) at the 10\% level of acceptance

Table 5. Possible Sources of Sign Asymmetry of Exchange Rate Exposure: Monthly Data

\begin{tabular}{|c|c|c|c|}
\hline & $\beta 2>0$ & $\beta 2=0$ & $\beta 2<0$ \\
\hline$\beta 3>0$ & $\begin{array}{l}\text { \#Net Exporters } \\
\text { \#Pricing-to-Market } \\
\text { With Market } \\
\text { Share Objective } \\
\text { \#Hysteresis } \\
\text { 0 firm (0.00\%) }\end{array}$ & $\begin{array}{l}\text { \#Net Exporters } \\
\text { \#Pricing-to-Market } \\
\text { With Market } \\
\text { Share Objective } \\
\text { \#Hysteresis } \\
\mathbf{1} \text { firm (0.98\%) }\end{array}$ & $\begin{array}{l}\text { \#Net Importers } \\
\text { \#Pricing-to-Market } \\
\text { With Market Share } \\
\text { Objective } \\
\\
\mathbf{2} \text { firms (1.96\%) }\end{array}$ \\
\hline $\boldsymbol{\beta 3}=\mathbf{0}$ & $\begin{array}{l}\text { \#Net Exporters } \\
\text { \#Symmetric } \\
\text { Exposure } \\
\text { o firm (0.00\%) }\end{array}$ & $\begin{array}{l}\text { \#Net Exporters or } \\
\text { Importers } \\
\text { \#No Exposure } \\
\mathbf{3 1} \text { firms (30.39\%) }\end{array}$ & \begin{tabular}{|l} 
\#Net Importers \\
\#Symmetric \\
Exposure \\
60 firms $(\mathbf{5 8 . 2 2 \% )}$
\end{tabular} \\
\hline $\boldsymbol{\beta 3}<\mathbf{0}$ & \begin{tabular}{|l} 
\#Net Exporters \\
\#Pricing-to-Market \\
Under Volume \\
Constraints \\
\#Asymmetric Hedging \\
0 firm (0.00\%)
\end{tabular} & $\begin{array}{l}\text { \#Net Importers } \\
\text { \#Pricing-to-Market } \\
\text { Under Volume } \\
\text { Constraints } \\
\text { \#Asymmetric Hedging } \\
\mathbf{5} \text { firms (4.90\%) }\end{array}$ & $\begin{array}{l}\text { \#Net Importers } \\
\text { \#Asymmetric Hedging }\end{array}$ \\
\hline
\end{tabular}

Adopted from Koutmos and Martin (2003) at the 10\% level of acceptance

Results here are not comparable with Koutmos and Martin (2003); their unit being the country-sector, but they reported that $63 \%$ of non-US cases were not exposed to exchange rate changes, while only $10.48 \%$ and $30.39 \%$ (respectively for daily and monthly data) of our Taiwanese sample were not exposed.

Their sample showed a higher percentage of firms displaying a sign asymmetry: $16 \%$, compared to $14.29 \%$ and $10.78 \%$ for our daily and monthly data. Additionally, $22 \%$ of their non-US sample was symmetrically exposed while we found a higher percentage for our sample: $75.24 \%$ and $58.22 \%$. 
Our findings reveal that more Taiwanese firms are exposed to exchange rate changes but less are displaying a sign asymmetry.

Interestingly, the sign asymmetry is much more frequent in our daily data therefore the figures are too large to be ignored. We notice here a dichotomy: if all the sign asymmetry coefficients (but one) are negative for the daily data, about $27 \%$ (of the concerned firms) are positive and $73 \%$ negative for the monthly data.

On average, the sign asymmetry coefficient has a higher impact when the coefficient is negative (-2.978) than when it is positive (2.195). It means that not only do more firms display a benefit from a daily or monthly appreciation of the domestic currency but the impact of an appreciation is also greater than from a depreciation of the currency.

\subsubsection{Magnitude Asymmetry in Exchange Rate Exposure}

We also noticed a dichotomy for the firms displaying a magnitude asymmetry but the horizon here has an opposite effect. In our study $69 \%$ of the concerned firms display a positive daily magnitude asymmetry coefficient, but only $50 \%$ in the monthly case.

On average, when the daily coefficient is negative, the impact is larger than for positive coefficients: -0.500 compared to 0.426 , but the situation is reversed when we consider the monthly data: 2.191 compared to -1.912 .

More tests should be conducted on the threshold level for which the reaction from the firms is stronger. Our results show that almost $88 \%$ of the Taiwanese firms are exposed to a small exchange rate change at the daily horizon and $94 \%$ at the monthly horizon. For firms displaying a magnitude asymmetry, the impact on their returns depends on the sign of the exchange rate variation.

At the daily horizon, $69.23 \%$ of the concerned firms suffered from a large appreciation of the domestic currency while $30.77 \%$ benefited from it. The percentage of firms suffering from a large appreciation of the TWD decreases to $50 \%$ at the monthly horizon. It is difficult to explain precisely the role of the horizon here, but the consequence for a firm displaying a magnitude asymmetry is to reduce the level of foreign exchange exposure (all having a negative sign) and thus the benefit from an appreciation of the domestic currency.

\subsubsection{Asymmetric Volatility Underlying Exchange Rate Exposure}

As mentioned before, if the percentage of firms displaying sign and magnitude asymmetries decreases with the horizon, the situation is reversed for the volatility asymmetry: it increases from $38.10 \%$ to $56.86 \%$ (respectively for daily and monthly data at the $10 \%$ level of significance).

From table 3, we see that the percentage of firms exposed to the exchange rate risk displaying a volatility asymmetry is respectively $35.24 \%$ and $37.25 \%$ for daily and monthly data, showing an increase also with the horizon.

But the percentage of the firms displaying simultaneously sign and volatility asymmetries is much lower: $4.76 \%$ and $4.90 \%$ respectively for daily and monthly data as well as for the firms displaying simultaneously magnitude and volatility asymmetries $4.76 \%$ and $3.92 \%$ respectively for daily and monthly data.

Only $2.86 \%$ of the exposed firms display simultaneously at the daily horizon, the three forms of asymmetry ( $0.98 \%$ at the monthly horizon) but $60 \%$ of the exposed firms display at least one form of asymmetry at the daily horizon and $76.47 \%$ at the monthly horizon.

Not indicated on the above tables, we found that even though they do not show a statistically significant exchange rate exposure, three firms $(2.86 \%$ of our sample) display a volatility asymmetry at the daily horizon (two positive and one negative) and 20 (19.61\%) at the monthly horizon (eight positive and 12 negative). So, although the mechanism of the volatility asymmetry is not very clear at the firm level, it is too remarkable to be ignored especially at the monthly horizon.

A positive volatility asymmetry coefficient is associated to bad news, thus increasing the volatility of the asset's return but considering exchange rates, a change does not necessarily mean bad or good news. It will of course depend on the situation of the firm.

Following our tables 4 and 5, both net exporters and importers are included in our sample so it seems logical to observe a dichotomy in the sign of the volatility asymmetry coefficient. But when we compare both horizons, the majority of the signs are negative at the daily horizon (62.50\%) but positive at the monthly horizon (60.34\%). This implies that explaining the mechanism underlying volatility asymmetry is somehow difficult.

\section{Concluding Remarks}

Understanding the impact of foreign exchange risk is critical for purposes of firm valuation and risk management. In other words, it is important to understand if (and how) stock returns are linked to exchange rate fluctuations. 
But it is surprising that most of the previous studies having investigated this issue obtain mixed results hence the term "exchange rate exposure puzzle". Bartram and Bodnar (2007) consider that financial and operational hedging are the main explanation, and not the sampling or the models used.

However, encouraging results (still not as good as one may expect in regard of the financial theory) are obtained when authors focus on small and open economies, see for example Moran (2005) with his Chilean sample, or Chen et al. (2004) who find that exchange rate changes affect the value of New Zealand firms.

That is the reason why we investigate the case of Taiwan, which is one of the most open economies in the word. Using a sample of 107 publicly traded Taiwanese firms, from $6^{\text {th }}$ June 1990 to $14^{\text {th }}$ July 2010 , we test our hypothesis according to which open economy is a good laboratory for investigating the exchange rate exposure puzzle.

Our contributions to the exposure literature may be summarized as followed:

1. The hypothesis, according to which a small open economy is better to study exposure, is largely confirmed.

2. As far as we know, we obtain (among the previous publications) the highest level of exposure: almost $90 \%$ and $64 \%$ for respectively daily and monthly data. Even the results from Chen et al. (2004) and Moran (2005) who also studied small open economies, exhibit that only about $25 \%$ of their sample are exposed.

3. Taiwanese firms exhibit mostly a symmetric profile, even though the percentage of the company with an asymmetric behavior is too high to be ignored.

4. $100 \%$ of the exposed firms are negatively exposed: Taiwanese firms benefit from an appreciation of the domestic currency (TWD).

5. Our results may lead to the fact that the exposure puzzle we mentioned in our introduction may be a consequence of sample selection and methodological limitations of earlier studies.

6. Industry is not an explanatory variable, at least for Taiwanese firms.

We find that Taiwanese firms are statistically and economically strongly exposed to exchange rate changes and display an exposure coefficient which increases sharply with the time horizon.

When we take into account simultaneously all forms of asymmetry: sign, magnitude and volatility, $88.57 \%$ and $63.73 \%$ (respectively for daily and monthly data) are exposed to exchange rate fluctuations. It seems that the percentage decreases with the time horizon. It might be explained by the fact that GARCH specifications are more efficient with high frequency data.

To our knowledge, this high percentage is not found in previous studies. Moreover, $100 \%$ of the concerned firms are negatively exposed, which means that all benefit from an appreciation of the domestic currency.

Obviously this result is not conformed to the conventional wisdom but it is similar to the findings of Muller and Verschoor (2007), Chen et al. (2004) and Moran (2005) who use respectively an Asian, a New Zealand and a Chilean sample. But Chen et al. (2004) found opposite results when using AUD and Moran (2005) obtained a negative exposure but only on average. Moreover when we compare our results with the ones obtained when studying small economies, Chen et al. (2004) did not analyze asymmetric exposure and Moran (2005) did not find any evidence of asymmetry.

Using the classification in Koutmos and Martin (2003) we see that only $10.48 \%$ and $30.39 \%$ (respectively for daily and monthly data) of our sample are not exposed. If for our daily and monthly data, $75.24 \%$ and $58.22 \%$ of Taiwanese firms are symmetrically exposed, respectively $14.29 \%$ and $10.78 \%$ display a sign asymmetry. Almost $88 \%$ of the Taiwanese firms are exposed to a small exchange rate change at the daily horizon and $94 \%$ at the monthly horizon, which is coherent with a concave behavior.

The majority of firms displaying a sign asymmetry benefit from an appreciation of the domestic currency (increasing their exposure) while companies having a magnitude asymmetry profile tend to benefit from a depreciation of the currency (reducing their exposure).

The percentage of exposed firms displaying a volatility asymmetry is respectively $35.24 \%$ and $37.25 \%$ for daily and monthly data, which shows an increase with the horizon.

Not indicated in our tables, we find that even though they do not show a statistically significant exchange rate exposure, three firms $(2.86 \%$ of our sample) display a volatility asymmetry at the daily horizon (two positive and one negative) and $20(19.61 \%)$ at the monthly horizon (eight positive and 12 negative). So, although the mechanism of the volatility asymmetry is not very clear at the firm level, it is too remarkable to be ignored especially at the monthly horizon. 
Both net exporters and importers are included in our sample so it seems logical to observe a dichotomy in the sign of the volatility asymmetry coefficient. But when we compare both horizons, the majority of the signs are negative at the daily horizon $(62.50 \%)$ but positive at the monthly horizon (60.34\%). This implies that explaining the mechanism underlying volatility asymmetry is somehow difficult.

This study confirms that an open economy allows a better investigation of the exchange rate exposure puzzle, and the entire currency risk actually faced by firms is not fully captured by the traditional exposure coefficient alone. It seems also that the negligence of multiple asymmetries may overestimate exchange rate exposure.

Knowing their asymmetric profile, firms can appropriately choose their hedging instruments. A non negligible part of our sample displays an asymmetric exposure, but the majority is symmetrically exposed.

Thus, Forwards and Futures may be more appropriate for them. The government should then put more effort into upgrading these financial markets. Investors may also benefit from knowing the exposure profile of their targets.

If for example they decide to invest in the stocks of a Taiwanese exporter with market share objective, they will have to know that the stock returns will positively respond to an appreciation of the domestic currency.

The data we collected (about the firms) are mostly the stock prices, so our results can be compared to the ones described in the earlier literature. If we still could make significant conclusions, our set of data and models can not answer to questions related to the level and sign of exposure.

As mentioned before, industry is not an explanatory variable, at least for Taiwan. But other factors may provide explanations this research could not. So we should from now, focus on a better understanding of the Taiwanese exposure, by using a different set of data and models.

Firstly, did the two financial crises have an impact on the level of Taiwanese exposure?

Secondly, the largest part of the transactions in the Taiwan Stock Exchange is made by the Electronic sector. We should verify is the exposure behavior of these firms is similar to the ones we obtained with this research, which did not focus on any industry in particular.

Thirdly, we should use the available financial data (balance sheet, income statement...) to investigate in details the determinants of the Taiwanese exposure, in view to answer some questions as: why a so high percentage of companies are exposed and why they only benefit from an appreciation of the domestic currency.

\section{References}

Adler M., \& Dumas B. (1984). Exposure to Currency risk: Definition and Measurement. Financial Management, 13, 41-50. http://dx.doi.org/10.2307/3665446

Allayannis G., \& Ofek E., (2001). Exchange Rate Exposure, Hedging and the Use of Foreign Currency Derivatives. Journal of International Money and Finance, 20, 273-296. http://dx.doi.org/10.1016/S0261-5606(00)00050-4

Amihud, Y. (1994). Evidence on Exchange Rates and Valuation of Equity Shares, in Y. Amihud and R.M. Levich, Eds. Exchange Rates and Corporate Performance. Irwin Professional Publishing, New York, 49-59

Andren, N. (2001). Is macroeconomic exposure asymmetric? Department of Business Administration, Lund University, Working Paper

Atindehou, R. B., \& Gueyie, J. P. (2001). Canadian chartered banks' stock returns and exchange rate risk. Management Decision, 39, 285-295. http://dx.doi.org/10.1108/EUM0000000005463

Baldwin, R. (1988). Hysteresis in import prices: the Beachheld effect. American Economic Review, 78, 773-785.

Bartram S. M. (2004). Linear and Nonlinear foreign Exchange Rate exposure of German Non Financial Corporation. Journal of International Money and Finance, 23, 673-699.

Bartram, S. M., \& Bodnar, G.M. (2007). The exchange rate exposure puzzle. Managerial Finance, 33(9), 642-666.

Bartram, S. M., Brown, G. W., \& Minton B. A. (2010). Resolving the exposure puzzle: The many facets of exchange rate exposure. Journal of Financial Economics, 95, 148-173.

Bodnar G. M., Dumas B., \& Marston R. C. (2002). Pass-Trough and Exposure. Journal of Finance, 57(1), 199-231. http://dx.doi.org/10.1111/1540-6261.00420 
Bodnar G. M., \& Gentry W. M. (1993). Exchange Rate Exposure and Industry Characteristics: Evidence from Canada, Japan and the USA. Journal of International Money and Finance, 12, 29-45. http://dx.doi.org/10.1016/0261-5606(93)90008-Y

Bodnar G. M., \& Wong M. H. F. (2000). Estimating Exchange Rate Exposures: Some "Weighty" Issues. NBER Working Paper Series. Working Paper No. 7497

Carter D. A., Pantzalis C., \& Simkins B. J. (2005). Asymmetric exposure to foreign-exchange risk: financial and real option hedges implemented by U.S. multinational corporations. Oklahoma State University, Stillwater, Working Paper

Chen J., Naylor M., \& Lu, X. (2004). Some Insights into the Foreign Exchange Pricing Puzzle: Evidence from a Small Open Economy. Pacific-Basin Finance Journal, 12, 41-64. http://dx.doi.org/10.1016/S0927-538X(03)00020-9

Dixtit, A. (1989). Entry and exit decisions under uncertainty. Journal of Political Economy, 97, 620-638.

Dominguez K. M. E., \& Tesar L. L. (2001). A Re-Examination of Exchange Rate Exposure. NBER Working Paper Series. Working Paper No. 8128.

Dominguez, K., \& Tesar, L. (2006). Exchange rate exposure. Journal of International Economics, 68, 188-218. http://dx.doi.org/10.1016/j.jinteco.2005.01.002

Friberg R., \& Nydahl S. (1999). Openness and the Exchange Rate Exposure of National Stock Markets. International Journal of finance and Economics, 4(1), 55-62. http://dx.doi.org/10.1002/(SICI)1099-1158(199901)4:1<55::AID-IJFE90>3.0.CO;2-1

Froot, K. A., \& Klemperer P. D. (1989). Exchange rate pass-through when market share matters. Economic Review, 79, 637-654.

Giurda, F., \& Tzavalia, E. (2004). Is the currency risk priced in equity markets? Department of Economics, Queen Mary University of London. Working Paper 511

Griffin J., \& Stulz R. (2001). International Competition and Exchange Rate Shocks: A Cross-Country Industry Analysis of Stock Returns. Review of Financial Studies, spring, 14(1), 215-241. http://dx.doi.org/10.1093/rfs/14.1.215

Heckman, C. (1985). A Financial model of foreign exchange exposure. Journal of International Business Studies, Summer, 83-99. http://dx.doi.org/10.1057/palgrave.jibs.8490452

Hung, J. (1992). Assessing the Exchange Rate's Impact on U.S. Manufacturing Profits. Quarterly Review, Federal Reserve Bank of New York, Quarterly 4, 44-63

Jorion P. (1990). The Exchange-Rate Exposure of U.S. Multinationals. Journal of Business, 63(3), 331-345. http://dx.doi.org/10.1086/296510

Jorion P. (1991). The Pricing of Exchange Rate Risk in the Stock Market. Journal of Financial and Quantitative Analysis, 26(3), 363-376. http://dx.doi.org/10.2307/2331212

Kanas, A. (2000). Volatility spillovers between stock returns and exchange rate changes. Journal of Business and Finance and Accounting, 27(3-4), 447-467. http://dx.doi.org/10.1111/1468-5957.00320

Khoo, A. (1994). Estimation of Foreign Exchange Exposure: an Application to Mining Companies in Australia. Journal of International Money and Finance, 13, 342-363. http://dx.doi.org/10.1016/0261-5606(94)90032-9

Knetter, M. M. (1994). Is export price adjustment asymmetric: evaluating market share and marketing bottlenecks hypotheses. Journal of International Money and Finance, 13, 55-70. http://dx.doi.org/10.1016/0261-5606(94)90024-8

Koutmos G., \& Martin A. D. (2003). Asymmetric Exchange Rate Exposure: Theory and Evidence. Journal of International Money and Finance, 22, 365-383. http://dx.doi.org/10.1016/S0261-5606(03)00012-3

Maghrebi, N., Holms, M. J., \& Pentecost, E. J. (2006). Are there asymmetries in the relationship between exchange rate fluctuations and stock market volatility in Pacific Basin Countries? Review of Pacific Basin Financial Markets and Policies, 9(2), 229-256. http://dx.doi.org/10.1142/S0219091506000719

Mark, N.C. (1990). Real and nominal exchange rates in the long run: an empirical investigation. Journal of International Economics, 28, 115-136. http://dx.doi.org/10.1016/0022-1996(90)90052-N 
Marston, R. (1990). Pricing to market in Japanese manufacturing. Journal of International Economics, 29, 217-236. http://dx.doi.org/10.1016/0022-1996(90)90031-G

Miller K. D., \& Reuer J. J. (1998). Asymmetric Corporate Exposures to Foreign Exchange Rate Changes. $\begin{array}{llll}\text { Strategic Management } \quad \text { Journal, } & 19(12), & 183-1191 .\end{array}$ http://dx.doi.org/10.1002/(SICI)1097-0266(1998120)19:12<1183::AID-SMJ1>3.3.CO;2-J

Moran, P. (2005). Foreign Exchange Exposure of Chilean Firms, Facultad de Ciencias Empresariales, Universidad de Talca, Chile, Working Paper.

Muller, A., \& Verschoor W. F. C. (2006). Asymmetric foreign exchange risk exposure: evidence from U.S. multinational firms. Journal of Empirical Finance, 13, 495-518. http://dx.doi.org/10.1016/j.jempfin.2006.01.003

Muller, A., \& Verschoor W. F. C. (2007). Asian foreign exchange risk exposure. Journal of the Japanese and International Economies, 21, 16-37.

Rosenberg, M. (2003). Exchange Rate Determination. McGraw Hill.

Rossi Jr., J. L. (2008). Corporate foreign vulnerability, financial policies and the exchange rate regime: evidence from Brazil, Insper, IBMEC Sao Paulo, Working Paper.

Rossi Jr., J.L. (2009). Nonlinear foreign exchange exposure: evidence from Brazilian companies, Insper, IBMEC Sao Paulo, Working Paper 189/2009

Tai, C. (2005). Asymmetric currency exposure of U.S. bank stock returns. Journal of Multinational Financial Management, 15, 455-472.

Williamson R. (2001). Exchange Rate Exposure and Competition: Evidence from the Automotive Industry. Journal of financial Economics, 59, 441-475. 